\title{
Milk consumption in relation to incidence of nasopharyngeal carcinoma in 48 countries/regions
}

\author{
Zhi-Ming Mai ${ }^{1,3}$, Ching-Man Lo ${ }^{1,3}$, Jun $\mathrm{Xu}^{1,3}$, King-Pan Chan ${ }^{1}$, Chit-Ming Wong ${ }^{1}$, Maria Li Lung ${ }^{2,3}$ \\ and Tai-Hing Lam ${ }^{1,3^{*}}$
}

\begin{abstract}
Background: Decreasing trends of nasopharyngeal carcinoma (NPC) incidence have been consistently reported in endemic populations but the etiology of NPC remains unclear. The objective of our study was to assess the international and local (Hong Kong) correlations of milk and dairy products per capita consumption with NPC incidence.

Methods: We conducted an ecological study in 48 countries/regions. Age standardized incidence rates of NPC were obtained from the Cancer Incidence in Five Continents. Dairy product consumption and Human Development Index were obtained from the Food and Agriculture Organization of the United Nations and the United Nations Development Programme. Spearman correlation, multivariate analysis and time-lagged analysis were performed.

Results: The negative correlations between milk consumption and decreased age standardized incidence rates of NPC were observed in the 48 countries/regions adjusting for Human Development Index in endemic countries/regions. In Hong Kong, multivariate analysis, after adjusting for other potential confounders, including salted fish, cigarette, vegetable consumption and socioeconomic status, showed consistently negative and significant correlations between milk consumption and NPC incidence (The strongest coefficient $(\beta)$ was observed at 10-year lag in males $[\beta=-0.439 ; P<0.01]$ and in females $[\beta=-0.258 ; P<0.01])$.
\end{abstract}

Conclusions: Our study showed the correlations on milk consumption per capita and against lower risk of NPC in 48 countries/regions and in Hong Kong. These hypothesis-generating results could support further studies on individual exposures and the disease.

Keywords: Milk consumption, Nasopharyngeal carcinoma, Ecological study, 48 countries/regions

\footnotetext{
* Correspondence: hrmrlth@hkucc.hku.hk

'School of Public Health, Li Ka Shing Faculty of Medicine, The University of Hong Kong, 5/F, William MW Mong Block, 21 Sassoon Road, Hong Kong S.A.R., China

${ }^{3}$ Center for Nasopharyngeal Carcinoma Research (CNPCR), Research Grants Council Area of Excellence Scheme, The University of Hong Kong, Hong Kong S.A.R., China

Full list of author information is available at the end of the article
} 


\section{Background}

Nasopharyngeal carcinoma (NPC) is rare worldwide, but much more common in Southeast Asia [1]. One of the highest age-standardized incidence rates (ASIRs) of NPC was observed in Hong Kong (12.5 per $10^{5}$ person-years in males, 2012) [2], and similar ASIRs were observed in nearby cities including Zhongshan and Guangzhou, southern China [3]. By contrast, the ASIRs for most part of the world are less than 0.5 per $10^{5}$ person-years [3]. In addition to the marked geographic incidence pattern of NPC, decreasing trends of NPC incidence have been consistently reported in endemic populations [4]. In Hong Kong, for example, NPC was the $8^{\text {th }}$ most common cancer in 2012; however, the ASIR in males and females combined decreased by 68 \% during 1983 to 2012 [2]. The endemic regions of NPC were marked by rapid economic growths and these growths might be associated with the observed declines [5], but the underlying causes are unclear.

Economic development may have a link with the changes of lifestyle, including decreased consumption of preserved foods and increased consumption of various food [5]. Cantonese-style salted fish was a staple preserved foods in southern China because they were cheap. It is considered as a major NPC risk factor and has been rated as a Group 1 carcinogen by the International Agency for Research on Cancer [6]. However, our recent ecological study did not find a correlation between the decline in salted fish consumption per capita and the corresponding changes in NPC incidence in 8 regions with varied NPC risk, including Hong Kong which has the highest risk [7]. The decreasing trend of NPC incidence may be due to other risk or protective factors.

The World Cancer Research Fund suggests that approximately $30-40 \%$ of cancer cases are potentially preventable through changes in food consumption patterns [8]. Milk consumption has greatly increased in Asia, though is still far lower than Western countries [9]. Differences in milk consumption and in the incidence of NPC among populations worldwide are distinct. The limited evidence of milk consumption and NPC came from case-control studies, and majority of these in endemic regions were conducted two decades ago before the changes of dietary patterns with rapid economic development. The correlation between milk consumption and NPC remains unclear, and new evidence is needed. Case-control or cohort studies take some years to deliver results and should be conducted to test the hypothesis generated by ecological studies. Ecological study is the most costeffective approach to assess the population disease impact from changes over several decades in the consumption of food items that are suspected to be harmful or protective, and can provide quick albeit preliminary evidence at low cost. A notable example is that the hypothesis of the correlation between higher milk consumption and increased risk of prostate cancer was generated from ecological studies [10], and has been later confirmed by further studies (case-control and cohort studies, and meta-analyses) which provide stronger evidence [11].

We therefore assessed the international and local (Hong Kong) correlations of milk and dairy products per capita consumption with NPC incidence.

\section{Methods}

A total of 48 countries/regions with comprehensive and reliable cancer and food statistics data were included.

\section{NPC incidence statistics}

ASIR for NPC (C11, ICD-10: The International Classification of Diseases 10th Revision) were obtained from Cancer Incidence in Five Continents, published by the International Agency for Research on Cancer, 1998-2002 (Vol. IX) [3]. All incidence data were adjusted to the Segi standard population [12]. The data collection procedures are shown in Appendix 1.

\section{Milk and dairy product consumption per capita in $\mathbf{4 8}$ countries/regions}

Per capita milk consumption data from 1968 to 2002 were obtained from two international sources. Food supply data, including those for "milk (whole)", "cheese", "butter and ghee", and "fresh cream", were obtained from the Food Supply database maintained by the Food and Agriculture Organization of the United Nations (FAO) (http://faostat.fao.org/). Milk excluding butter per capita consumption was estimated from import, export, and change in stock volumes provided in the Food Balance Sheet of the FAO according to the formula in the International Farm Comparison Network dairy report 2004 [(import export - change in stock) $\div$ total population of the different countries/regions]. The 1950-2010 population data were obtained from the World Population Prospects: the 2012 Revision (http://esa.un.org/wpp/unpp/panel_population.html) [13].

\section{Potential confounders}

Indicators of the social economic status of the 48 countries/regions were obtained from the Human Development Index (HDI) published by the United Nations, which includes national income, education and life expectancy. 
Salted fish, tobacco, vegetables consumption per capita, and Gross Domestic Product (GDP) per capita in multivariate analysis

Hong Kong has the highest ASIR among the 48 countries/regions, and has data on other risk factors. The data collection procedures have been described previously [7]. Briefly, per capita consumption of salted fish, tobacco and vegetables was estimated using the Service Centre on Trade Statistics, Census and Statistics Department, Hong Kong Special Administrative Region (HKSAR) Government, the Hong Kong Council on Smoking and Health via the General Household Survey and Thematic Household Survey 2008, and the Department Annual Report of the Agriculture, Fisheries and Conservation Department (procedures included in Appendix 2). The per capita GDP was obtained from the 2009 Gross Domestic Product (Yearly), Census and Statistics Department, HKSAR Government.

\section{Statistical analysis}

Spearman correlation analysis was used to examine the correlation between the ASIR of NPC and milk and dairy product consumption per capita (1998-2002). Six additional sets of correlation were calculated for consumption with the following time lags: 5-year (1993-1997), 10-year (1988-1992), 15-year (1983-1987), 20-year (1978-1982), 25-year (1973-1977) and 30-year (1968-1972).

Regression analysis was used to examine the correlation of milk consumption with the log NPC incidence adjusting for HDI in order to comply with the assumptions underlying outliers. In our analysis,

$$
\begin{aligned}
& \log (\text { ASIR of NPC })=\beta_{0}+\beta_{1}(\text { milk \& dairy product })_{i} \\
& +\beta_{2}(H D I)
\end{aligned}
$$

where $\beta_{0}$ is the intercept, $\beta_{1}$ and $\beta_{2}$ represent parameters in the multiplicative model for each milk and dairy products, and (Milk \& dairy product $)_{i^{-}}$ denotes each type of milk and dairy product, $i$ from 1 to 5 .

Each histopathological diagnosis of NPC has its unique epidemiologic profile: keratinizing squamous carcinoma is the main histological subtype in low-risk areas, while non-keratinizing undifferentiated carcinoma is the predominant subtype in endemic areas [14]. Countries/regions were stratified by low- and high-risk countries/regions of NPC to indirectly examine the correlation between milk consumption and histology-specific NPC incidence according to the GLOBOCAN 2012 [15] which showed the countries/ regions with the 20 highest ASIR of NPC in males in the world. Eight countries/regions in our analysis, including Hong Kong (ASIR of NPC: $17.82 / 10^{5}$ per person-years), Malaysia $\left(11.91 / 10^{5}\right)$, Mainland China $\left(11.65 / 10^{5}\right)$, Singapore $\left(10.92 / 10^{5}\right)$, Philippines (5.66/ $\left.10^{5}\right)$, Algeria $\left(5.08 / 10^{5}\right)$, Tunisia $\left(4.28 / 10^{5}\right)$ and Thailand $\left(2.94 / 10^{5}\right)$ were among the 20 countries/regions with the highest ASIR of NPC (Appendix 3). Our literature review showed that non-keratinizing undifferentiated carcinoma are the predominant subtype in these 8 high-risk countries/regions. The other 40 countries/regions with keratinizing squamous carcinoma as the predominant subtype were classified as low-risk (Appendix 4).

More detailed analysis was conducted for Hong Kong, which has the highest NPC risk and has reliable NPC and risk factors data. Multivariate linear regression analysis was performed between milk excluding butter (which was the only dairy item with available consumption data) consumption per capita and NPC incidence in Hong Kong, with adjustment for other recognized NPC risk factors (salted fish, cigarette smoking, vegetables consumption and socioeconomic status). Repeated analysis using various time lags (range: 0, 5, 10 years) of milk excluding butter consumption per capita prior to the ASIR of NPC was performed to test the robustness of estimates based on different assumptions in the latency period of cancer development subsequent to relevant exposures.

All analyses were performed using SPSS 20.0. $p<0.05$ was considered statistically significant.

Ethics approval was not required as data in our study were secondary data from Cancer Incidence in Five Continents series published by the International Agency for Research on Cancer (http://ci5.iarc.fr/) and the Food Supply database maintained by the Food and Agriculture Organization of the United Nations (FAO) (http://faostat.fao.org/). These data were not directly collected from humans or animals.

\section{Results}

\section{Correlation between NPC incidence and milk} consumption in $\mathbf{4 8}$ countries/regions

Spearman rank correlation coefficients $(\rho)$ for the a) cross-sectional and b) time-lagged analysis of the ASIR of NPC by different milk and dairy products are shown in Table 1.

\section{Cross-sectional analysis from 1998 to 2002 (Table 1)}

The strongest negative correlation was observed between the ASIR of NPC and fresh cream (CRF) in females $(\rho=-0.63 ; p<0.001)$. The second strongest significant, but moderately negative, correlation was 
Table 1 Spearman correlation coefficients in cross-sectional analysis and time-lagged analysis between the ASIR of NPC and milk and dairy consumption in 48 countries/regions, 1968-2002

\begin{tabular}{|c|c|c|c|c|c|c|c|c|}
\hline & & \multirow{2}{*}{$\begin{array}{l}\text { Cross sectional } \\
\text { 1998-2002 }\end{array}$} & \multicolumn{6}{|c|}{ Time-lagged (consumption period) } \\
\hline & & & $\begin{array}{l}1993-1997 \\
\text { (5-year lag) }\end{array}$ & $\begin{array}{l}1988-1992 \\
(10-)\end{array}$ & $\begin{array}{l}1983-1987 \\
(15-)\end{array}$ & $\begin{array}{l}1978-1982 \\
(20-)\end{array}$ & $\begin{array}{l}1973-1977 \\
(25-)\end{array}$ & $\begin{array}{l}1968-1972 \\
(30-)\end{array}$ \\
\hline \multirow{2}{*}{$\begin{array}{l}\text { Milk excluding butter (MEBC) } \\
(N=48)\end{array}$} & Males & $-0.55^{* * *}$ & $-0.54 * * *$ & $-0.53^{* * *}$ & $-0.53^{* * *}$ & $-0.54 * * *$ & $-0.54 * * *$ & $-0.56^{* * *}$ \\
\hline & Females & $-0.57^{* * *}$ & $-0.55^{* * *}$ & $-0.54^{* * *}$ & $-0.55^{* * *}$ & $-0.55^{* * *}$ & $-0.55^{* * *}$ & $-0.56^{* * *}$ \\
\hline \multirow[t]{2}{*}{ Milk, whole (MWF) $(N=46)$} & Males & $-0.35^{*}$ & $-0.44^{* *}$ & $-0.45^{* *}$ & $-0.46^{* *}$ & $-0.45^{* *}$ & $-0.47^{* *}$ & $-0.52^{* * *}$ \\
\hline & Females & $-0.29^{*}$ & $-0.40^{* *}$ & $-0.43^{* *}$ & $-0.46^{* *}$ & $-0.45^{* *}$ & $-0.47^{* *}$ & $-0.51^{* * *}$ \\
\hline \multirow[t]{2}{*}{ Cheese $(\mathrm{CHF})(N=43)$} & Males & $-0.40^{* *}$ & $-0.40^{* *}$ & $-0.36^{*}$ & $-0.33^{*}$ & $-0.34^{*}$ & $-0.36^{*}$ & $-0.37^{*}$ \\
\hline & Females & $-0.42^{* *}$ & $-0.40^{* *}$ & $-0.37^{*}$ & $-0.31^{*}$ & $-0.32^{*}$ & $-0.30^{*}$ & -0.29 \\
\hline \multirow[t]{2}{*}{ Butter \& Ghee (BGF) $(N=43)$} & Males & $-0.36^{*}$ & -0.29 & $-0.32^{*}$ & $-0.30^{*}$ & $-0.33^{*}$ & $-0.35^{*}$ & $-0.40^{* *}$ \\
\hline & Females & $-0.44^{* *}$ & $-0.36^{*}$ & $-0.38^{*}$ & $-0.38^{*}$ & $-0.39^{*}$ & $-0.40^{* *}$ & $-0.43^{* *}$ \\
\hline \multirow[t]{2}{*}{ Fresh Cream $(C R F)(N=30)$} & Males & $-0.53^{* *}$ & $-0.65^{* * *}$ & $-0.71 * * *$ & $-0.68^{* * *}$ & $-0.68^{* * *}$ & $-0.65^{* * *}$ & $-0.65^{* * *}$ \\
\hline & Females & $-0.63^{* * *}$ & $-0.71^{* * *}$ & $-0.75^{* * *}$ & $-0.72^{* * *}$ & $-0.67^{* * *}$ & $-0.62^{* * *}$ & $-0.58^{* * *}$ \\
\hline
\end{tabular}

ASIR age standardized incidence rate, NPC nasopharyngeal carcinoma

${ }^{*} p<0.05 ;{ }^{* *} p<0.01 ;{ }^{* * *} p<0.001$ (2-tailed)

observed in milk, excluding butter (MEBC) in males $(\rho=-0.55 ; p<0.001)$. In addition, negative and significant correlations were also observed in the categories of milk (whole) (MWF), cheese (CHF), and butter and ghee (BGF), with Spearman coefficients of -0.35 in males and -0.29 in females, -0.40 in males and -0.42 in females, and -0.36 in males and -0.44 in females, respectively.

\section{Time-lagged analysis in seven lagged models (Table 1)}

The strongest negative correlations between CRF and NPC were shown in a 10-year lagged model in males $(\rho=-0.71 ; p<0.001)$ and in females $(\rho=-0.75$; $p<0.001)$. The significant coefficients increased from the 5-year lag, were maximal at the 10-year lag in males and in females, and declined to the lowest values at the 30-year lag. MEBC, MWF, and BGF had similar patterns for their negative and significant correlations, where the Spearman coefficients increased monotonically. CHF showed a U-shape with significant coefficients in males, which became minimal at the 15-year lag in males and increased and peaked at the longest lag, but the pattern was unclear in females.

Figure 1 shows the negative nonlinear correlation between the ASIR of NPC and per capita consumption of milk excluding butter (MEBC) in 48 countries/regions. The other dairy items showed similar patterns (figures not shown, but are included in Appendix 5). The ASIR of NPC ranged from $0.16 / 10^{5}$ person-years (Ecuador) to $17.82 / 10^{5}$ (HKSAR) in males (>100-fold difference), and from $0.02 / 10^{5}$ (Ecuador) to $6.72 / 10^{5}$ (HKSAR) in females ( $>300$-fold difference). Per capita consumption of milk excluding butter varied markedly across the world ( $>60$-fold difference), from about $10 \mathrm{~kg} / \mathrm{capita} /$ year in China Mainland with lower milk consumption to about $640 \mathrm{~kg} /$ capita/year in New Zealand (Appendix 6).

\section{Regression analysis}

Table 2 shows that the standardized coefficients $(\mathrm{s} \beta)$ were consistently significant and negative between different milk and dairy product consumption per capita and the ASIR of NPC without adjustment. The strongest negative and significant correlations were observed in MEBC $\left(\mathrm{s} \beta^{\mathrm{c}}=-0.499\right.$ in males, $\mathrm{s} \beta^{\mathrm{c}}=-0.500$ in females; $p<0.001)$.

After adjusting for HDI, the negative and significant correlations (adjusted standardized coefficients [as $\beta]$ ) in MEBC (as $\beta^{\mathrm{a}}=-0.552$ in males, as $\beta^{\mathrm{a}}=-0.534$ in females; $p<0.01$ ) and MWF (as $\beta^{\mathrm{a}}=-0.344$ in males, $p<0.05$ and as $\beta^{\mathrm{a}}=-0.344$ in females; $p<0.05$ ) were found consistently, though the negative correlations between per capita consumption of other dairy products and the ASIR of NPC were attenuated and no longer statistically significant.

\section{Correlation between NPC incidence and milk consumption in high- and low-risk regions}

Table 3 shows that the standardized coefficients in high-risk and in low-risk regions with adjustment for HDI. Negative correlations were observed in high-risk regions, but were not statistically significant. In lowrisk regions, negative but insignificant coefficients were also observed in different dairy products with adjustment except for CRF with as $\beta^{1}=-0.444$ in males; $p=0.04$, and -0.375 in females; $p=0.08$ which was marginally significant. 

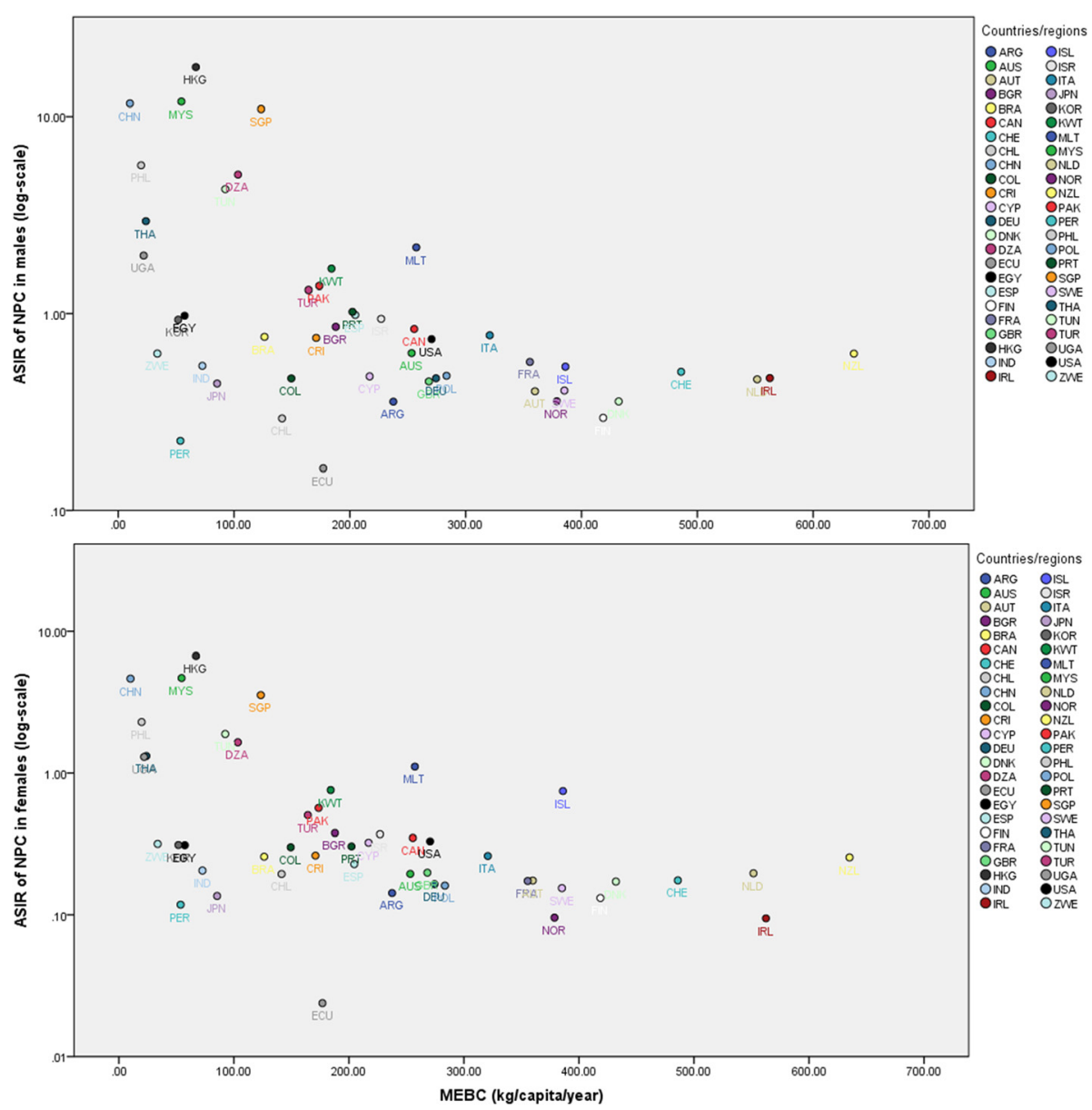

Fig. 1 Correlation between ASIR of NPC per $10^{5}$ person-years and per capita consumption of milk excluding butter (MEBC) in 48 countries/regions in males (top) and in females (bottom), 1998-2002

\section{Multivariate analysis in Hong Kong}

Table 4 shows that negative and significant correlations between per capita consumption of milk excluding butter and ASIR of NPC were observed in Hong Kong at three lagged periods in model 1 (adjusted for per capita consumption of vegetables, salted fish and cigarette smoking) and model 2 (model 1 with additional adjustments, for GDP). The strongest negative correlation in model 1 was observed at 10-year lag in males (the adjusted unstandardized coefficient $[\mathrm{au} \beta]=-0.454 ; P<0.05)$ and in females $(\mathrm{au} \beta=-0.232 ; P<0.01)$, and in model 2 at 10 -year lag in males $(\mathrm{au} \beta=-0.439 ; P<0.01)$ and in females $(\mathrm{au} \beta=-0.258 ; P<0.01)$.

\section{Discussion}

The present study showed negative and significant correlations between ASIR of NPC and milk consumption in 48 countries/regions. Countries/regions have different histopathological subtypes of NPC of varied etiology. This may be an important reason underlying the varying patterns of risk factors found across different countries/regions [16]. Our detailed analysis in 8 high-risk countries/regions with predominantly (over $85 \%$ ) Type 3 histopathological diagnosis of NPC (non-keratinizing undifferentiated carcinoma) showed negative but non-significant correlations between increased milk consumption and decreased NPC incidence adjusting for HDI. In Hong Kong with the highest NPC risk, we found negative and significant correlations after adjusting for additional potential confounders, including salted fish, cigarette, vegetables consumption and GDP per capita.

\section{Strengths and limitations}

Our study had several strengths, including the most comparable and reliable data, a global perspective (48 countries/regions) and a more detailed analysis on Hong Kong data with predominantly (over $95 \%$ ) 
Table 2 Regression coefficients between milk and dairy product consumption per capita and the ASIR of NPC in males and in females in 48 countries/regions, 1998-2002

\begin{tabular}{llll}
\hline & Sex & Without adjustment & Adjusting for HDI \\
& Males & Standardized coefficient $\left(s \beta^{\text {a }}\right)$ & Adjusted standardized coefficient (as $\left.\beta^{b}\right)$ \\
\hline MEBC $(N=48)$ & $-0.499^{* * *}$ & $-0.552^{* *}$ \\
MWF $(N=46)$ & Females & $-0.500^{* * *}$ & $-0.534^{* *}$ \\
& Males & $-0.436^{* *}$ & $-0.344^{*}$ \\
CHF $(N=43)$ & Females & $-0.438^{* *}$ & $-0.344^{*}$ \\
& Males & $-0.406^{* *}$ & -0.249 \\
BGF $(N=43)$ & Females & $-0.367^{*}$ & -0.208 \\
& Males & $-0.354^{*}$ & -0.251 \\
CRF $(N=30)$ & Females & $-0.340^{*}$ & -0.246 \\
& Males & $-0.497^{* *}$ & -0.325 \\
\hline Females & $-0.491^{* *}$ & -0.311
\end{tabular}

ASIR age standardized incidence rate, NPC nasopharyngeal carcinoma

$M E B C$ milk excluding butter, MWF milk (whole), CHF cheese, BGF butter \& ghee, CRF fresh cream

${ }^{*} p<0.05 ;{ }^{* *} p<0.01 ;{ }^{* * *} p<0.001$ (2-tailed)

${ }^{a}$ Crude

${ }^{b}$ Adjusted for Human Development Index

Type 3 of histopathological diagnosis of NPC (nonkeratinizing undifferentiated carcinoma) adjusting for potential confounders.

However, it also had several limitations. Although the FAO data are a cost-effective source for ecological comparisons and the best available data for a specific period in most countries/regions, these data did not represent real consumption in individuals (only the milk and dairy products available in the food supply). The major limitation is the ecological fallacy due to unmeasurable individual exposures and confounders.
There may be residual confounding. The factors that affect consumption at population level are not the same at individual level. At population level, there are many determinant of various nature and studies based on individual exposure factors are needed. We took account important and known factors by adjusting for the specific time-dependent covariates (socioeconomic status) in the global analysis, with additional adjustment of major confounders, including salted fish, cigarette and vegetables consumption and socioeconomic status for Hong Kong analysis. Race and

Table 3 Regression coefficients between milk and dairy consumption per capita and the ASIR of NPC in high- and low-risk countries/regions, 1998-2002

\begin{tabular}{|c|c|c|c|c|c|c|c|}
\hline & \multirow[b]{2}{*}{ Sex } & \multicolumn{3}{|c|}{ High-risk } & \multicolumn{3}{|c|}{ Low-risk } \\
\hline & & $\overline{N^{h}}$ & Adjusted standardized coefficient (as $\beta^{\text {h}}$ ) & $\overline{p \text { value }}$ & $\overline{N^{\prime}}$ & Adjusted standardized coefficient (as $\beta^{\prime}$ ) & $p$ value \\
\hline \multirow[t]{2}{*}{ MEBC } & Males & 8 & -0.122 & 0.75 & 40 & -0.125 & 0.54 \\
\hline & Females & & -0.254 & 0.50 & & -0.029 & 0.52 \\
\hline \multirow[t]{2}{*}{ MWF } & Males & 6 & -0.349 & 0.66 & 40 & -0.060 & 0.72 \\
\hline & Females & & -0.356 & 0.64 & & -0.091 & 0.59 \\
\hline \multirow[t]{2}{*}{$\mathrm{CHF}$} & Males & 6 & -0.003 & 0.99 & 37 & -0.022 & 0.92 \\
\hline & Females & & -0.055 & 0.95 & & -0.066 & 0.77 \\
\hline \multirow[t]{2}{*}{ BGF } & Males & 6 & -0.140 & 0.82 & 37 & -0.040 & 0.82 \\
\hline & Females & & -0.145 & 0.81 & & -0.048 & 0.79 \\
\hline \multirow[t]{2}{*}{ CRF } & Males & 4 & -0.631 & 0.44 & 26 & $-0.444^{*}$ & 0.04 \\
\hline & Females & & -0.662 & 0.40 & & -0.375 & 0.08 \\
\hline
\end{tabular}

$A S I R$ age standardized incidence rate, NPC nasopharyngeal carcinoma

$M E B C$ milk excluding butter, MWF milk (whole), CHF cheese, $B G F$ butter \& ghee, $C R F$ fresh cream

${ }^{*} p<0.05$ (2-tailed). Adjusted for Human Development Index

${ }^{\mathrm{h}}$ High-risk regions

' Low-risk regions 
Table 4 Regression coefficients from the multivariate linear regression analysis of ASIR of NPC on milk excluding butter (per kg), and various adjustments in Hong Kong, 1983-2009

\begin{tabular}{|c|c|c|c|c|c|c|}
\hline \multirow[t]{2}{*}{ Model } & \multirow{2}{*}{$\begin{array}{l}\text { Lagged period } \\
\text { (Years) }\end{array}$} & \multirow{2}{*}{$\begin{array}{l}\text { Consumption } \\
\text { variable }\end{array}$} & \multicolumn{2}{|l|}{ ASIR in males } & \multicolumn{2}{|l|}{ ASIR in females } \\
\hline & & & $\begin{array}{l}\text { Adjusted unstandardized } \\
\text { coefficients (auß) }\end{array}$ & $p$ value & $\begin{array}{l}\text { Adjusted unstandardized } \\
\text { coefficients (auß) }\end{array}$ & $p$ value \\
\hline \multirow[t]{3}{*}{1} & $0(N=27)$ & Milk excluding butter & $-0.349^{* * *}$ & $<0.001$ & $-0.155^{* * *}$ & $<0.001$ \\
\hline & $5(N=22)$ & & $-0.391^{* * *}$ & $<0.001$ & $-0.181^{* * *}$ & $<0.001$ \\
\hline & $10(N=17)$ & & $-0.454^{*}$ & $<0.05$ & $-0.232^{* *}$ & $<0.01$ \\
\hline \multirow[t]{3}{*}{2} & $0(N=27)$ & Milk excluding butter & $-0.419^{* * *}$ & $<0.001$ & $-0.184^{* * *}$ & $<0.001$ \\
\hline & $5(N=22)$ & & $-0.370^{* * *}$ & $<0.001$ & $-0.151^{* *}$ & $<0.01$ \\
\hline & $10(N=17)$ & & $-0.439^{* *}$ & $<0.01$ & $-0.258^{* *}$ & $<0.01$ \\
\hline
\end{tabular}

Model 1: adjusted for per capita consumption of vegetable, salted fish and cigarette smoking

Model 2: adjusted for per capita consumption of vegetable, salted fish, cigarette smoking, and per capita Gross Domestic Product

ASIR age standardized incidence rate, NPC nasopharyngeal carcinoma

${ }^{*} p<0.05 ;{ }^{* *} p<0.01 ;{ }^{* * *} p<0.001$ (2-tailed)

histology of NPC, are important factors for NPC studies, and should be taken into account in ecological analysis, but race- and histology-specific incidence data are not available in most cancer registries, suggesting that race- and histology-specific incidence data should be collected routinely to enable more indepth analysis. In addition, temporal sequence was unclear in the cross-sectional analysis to establish causality. Our time-lagged analysis was performed in 5-year to 30-year lagged periods. The results showed that negative and significant coefficients generally increased with longer time lag but with inconsistent patterns for different dairy products, warranting further investigations using longitudinal and time-series analysis for specific dairy products.

\section{Conclusions}

We found negative and significant correlations between milk and dairy products per capita consumption and NPC incidence in 48 countries/regions and in Hong Kong. These hypothesis-generating results could support further studies on individual exposures and the disease.

\section{Appendix 1}

There were four categories of countries/regions according to the different methods of data collection using the CI5, Vol. IX:

a) For the 16 countries (Australia, Brazil, France, Germany, India, Italy, Japan, China, Malaysia, Poland, Portugal, Spain, Switzerland, Thailand, Turkey, and United Kingdom), each with one or more cancer registries operating, the mean value of the ASIR from different cancer registries was calculated and used as the representative rate for the country. In Italy, for example, 22 ASIRs of NPC in 22 cancer registries were averaged, resulting in one mean value to represent the ASIR of NPC in Italy.

b) For 12 countries (Algeria, Egypt, Tunisia, Uganda, Zimbabwe, Argentina, Chile, Colombia, Ecuador, Peru, Pakistan, and the Philippines), only one cancer registry was operating in each. The ASIR of the single cancer registry was used to estimate the NPC incidence for the country.

c) The US has many cancer registries by different states. Among them, the registry for all racial groups in the Surveillance, Epidemiology, and End Results (SEER) Program of the National Cancer Institute (9 registries), which collected data in longer periods, was used as representative for the US.

d) For the remaining 19 countries/regions (Costa Rica, Canada, Cyprus, Israel, Korea, Kuwait, Austria, Bulgaria, Denmark, Finland, Hong Kong Special Administrative Region (HKSAR), Iceland, Ireland, Malta, The Netherlands, Norway, Singapore, Sweden and New Zealand), the cancer registries collected data for the whole country/region. The incidence rates for these countries/regions were used as provided.

In some countries (Zimbabwe, Israel, and Kuwait), analysis by ethnic groups was supported by some cancer registries. In our analysis, Zimbabwe included the African race as the representative population, Israel included all ethnic groups (both Jews and non-Jews), and Kuwait included Kuwaitis.

In a separate analysis, annual NPC ASIRs in Hong Kong from 1983 to 2009 were obtained from the Hong Kong Cancer Registry with the 1966 world standard population as reference. 


\section{Appendix 2}

Table 5 Sources of data and years of data availability from 4 regions

\begin{tabular}{|c|c|c|c|c|c|}
\hline Countries/regions & $\begin{array}{l}\text { Age-standardized } \\
\text { incidence rate }\end{array}$ & $\begin{array}{l}\text { Salted fish } \\
\text { consumption }\end{array}$ & $\begin{array}{l}\text { Vegetable } \\
\text { consumption }\end{array}$ & $\begin{array}{l}\text { Cigarette } \\
\text { consumption }\end{array}$ & $\begin{array}{l}\text { Gross domestic } \\
\text { product }\end{array}$ \\
\hline Hong Kong & $\mathrm{HKCR}^{\dagger}, 1983-2009$ & SCTS $^{\neq}, 1983-2009$ & $\mathrm{AFCD}^{\S}, 1983-2009$ & COSH", 1983-2009 & $\mathrm{HKCR}^{\dagger}, 1983-20$ \\
\hline
\end{tabular}

${ }^{\dagger}$ Hong Kong Cancer Registry

* Service Centre on Trade Statistics, Census and Statistics Department, Hong Kong Special Administrative Region Government

$\S$ Agriculture, Fisheries and Conservation Department, Hong Kong

" Hong Kong Council in Smoking and Health

\section{Appendix 3}

Table 6 Baseline characteristics of 8 high-risk countries/regions, 1998-2002

\begin{tabular}{|c|c|c|c|c|c|c|c|}
\hline High-risk regions & ASIRM & ASIRF & MEBC & MWF & $\mathrm{CHF}$ & BGF & CRF \\
\hline Algeria & 5.08 & 1.65 & 111.44 & 72.42 & 0.60 & 0.34 & - \\
\hline Tunisia & 4.28 & 1.89 & 101.12 & 79.14 & 0.56 & 0.50 & 0.14 \\
\hline China & 11.65 & 4.65 & 11.64 & 8.40 & 0.18 & 0.10 & - \\
\hline HKSAR & 17.82 & 6.72 & 67.53 & - & - & - & - \\
\hline Singapore & 10.92 & 3.56 & 124.64 & - & - & - & - \\
\hline Malaysia & 11.91 & 4.69 & 50.59 & 18.14 & 0.16 & 0.38 & 0.12 \\
\hline Philippines & 5.66 & 2.29 & 19.18 & 4.28 & 0.20 & 0.12 & 0.02 \\
\hline Thailand & 2.94 & 1.32 & 21.94 & 9.98 & 0.00 & 0.20 & 0.00 \\
\hline Average & 8.78 & 3.35 & 63.51 & 32.06 & 0.28 & 0.27 & 0.07 \\
\hline
\end{tabular}

ASIRM ASIR of NPC in males, ASIRF ASIR of NPC in females, MEBC milk excluding butter using International Farm Comparison Network report 2004, MWF whole milk collected from Food Balance Sheets, CHF cheese collected from Food Balance Sheets, BGF butter \& ghee collected from Food Balance Sheets, CRF fresh cream collected from Food Balance Sheets 


\section{Appendix 4}

Table 7 Baseline characteristics of 40 low-risk countries/regions, 1998-2002

\begin{tabular}{|c|c|c|c|c|c|c|c|}
\hline Low-risk regions & ASIRM & ASIRF & MEBC & MWF & $\mathrm{CHF}$ & BGF & CRF \\
\hline Egypt & 0.98 & 0.31 & 60.99 & 14.14 & 6.82 & 2.18 & - \\
\hline Uganda & 1.97 & 1.30 & 22.68 & 21.44 & - & - & - \\
\hline Zimbabwe & 0.63 & 0.32 & 36.22 & 27.18 & 0.30 & 0.24 & 0.10 \\
\hline Argentina & 0.36 & 0.14 & 229.70 & 99.56 & 11.64 & 1.32 & 0.12 \\
\hline Brazil & 0.76 & 0.26 & 126.82 & 105.34 & 0.34 & 0.48 & - \\
\hline Chile & 0.29 & 0.19 & 138.64 & 65.50 & 3.66 & 0.80 & - \\
\hline Colombia & 0.47 & 0.30 & 153.52 & 115.82 & 1.32 & 0.50 & - \\
\hline Costa Rica & 0.75 & 0.26 & 180.46 & 148.02 & 1.90 & 1.18 & - \\
\hline Ecuador & 0.16 & 0.02 & 208.97 & 92.18 & 0.60 & 0.40 & - \\
\hline Peru & 0.23 & 0.12 & 53.05 & 42.78 & 0.34 & 0.20 & - \\
\hline Canada & 0.84 & 0.35 & 254.72 & 55.48 & 11.70 & 2.86 & 6.36 \\
\hline USA & 0.74 & 0.33 & 270.99 & 122.52 & 14.46 & 2.10 & 0.00 \\
\hline Cyprus & 0.48 & 0.32 & 216.48 & 104.22 & 4.94 & 1.00 & 0.24 \\
\hline India & 0.54 & 0.21 & 75.71 & 39.54 & - & 2.00 & - \\
\hline Israel & 0.94 & 0.37 & 225.39 & 75.92 & 16.62 & 0.76 & - \\
\hline Japan & 0.44 & 0.14 & 84.00 & 50.34 & 2.48 & 0.68 & - \\
\hline Korea & 0.93 & 0.31 & 55.74 & 15.38 & 0.50 & 1.18 & 0.10 \\
\hline Kuwait & 1.69 & 0.76 & 171.09 & 77.90 & 6.96 & 2.38 & 1.42 \\
\hline Pakistan & 1.38 & 0.57 & 177.94 & 85.76 & - & 3.42 & - \\
\hline Turkey & 1.32 & 0.50 & 151.31 & 94.50 & 2.04 & 1.86 & - \\
\hline Austria & 0.40 & 0.17 & 350.64 & 83.12 & 19.14 & 5.06 & 3.92 \\
\hline Bulgaria & 0.86 & 0.38 & 193.92 & 103.82 & 7.60 & 0.30 & 0.04 \\
\hline Denmark & 0.36 & 0.17 & 442.34 & 52.92 & 16.02 & 1.68 & 9.14 \\
\hline Finland & 0.29 & 0.13 & 417.16 & 132.52 & 14.80 & 5.26 & 6.44 \\
\hline France & 0.57 & 0.17 & 356.50 & 63.24 & 23.36 & 8.68 & 5.40 \\
\hline Germany & 0.47 & 0.16 & 278.57 & 62.38 & 18.80 & 6.70 & 7.32 \\
\hline Iceland & 0.54 & 0.75 & 382.65 & 94.94 & 14.86 & 4.36 & 7.14 \\
\hline Ireland & 0.47 & 0.09 & 605.87 & 190.88 & 8.90 & 3.10 & 8.10 \\
\hline Italy & 0.78 & 0.26 & 322.29 & 41.58 & 21.42 & 3.02 & 3.42 \\
\hline Malta & 2.16 & 1.11 & 266.57 & 88.98 & 12.66 & 0.46 & 0.12 \\
\hline Norway & 0.36 & 0.10 & 360.72 & 77.42 & 14.84 & 2.90 & 7.52 \\
\hline Poland & 0.48 & 0.16 & 284.82 & 64.36 & 11.72 & 4.40 & 4.08 \\
\hline Portugal & 1.02 & 0.30 & 219.12 & 61.72 & 8.36 & 1.98 & 1.14 \\
\hline Spain & 0.98 & 0.23 & 206.56 & 105.40 & 6.38 & 0.72 & 1.70 \\
\hline Sweden & 0.41 & 0.15 & 386.71 & 79.48 & 16.98 & 3.70 & 9.82 \\
\hline Switzerland & 0.51 & 0.18 & 479.55 & 95.46 & 16.86 & 6.10 & 0.58 \\
\hline Netherlands & 0.46 & 0.20 & 529.64 & 119.28 & 20.14 & 2.76 & 0.78 \\
\hline UK & 0.45 & 0.20 & 266.88 & 121.84 & 9.78 & 3.26 & 0.02 \\
\hline Australia & 0.63 & 0.19 & 256.36 & 100.78 & 9.26 & 3.04 & - \\
\hline New Zealand & 0.63 & 0.25 & 669.59 & 55.78 & 4.84 & 8.18 & 0.20 \\
\hline Average & 0.72 & 0.31 & 254.27 & 81.24 & 9.82 & 2.59 & 3.28 \\
\hline
\end{tabular}

ASIRM ASIR of NPC in males, ASIRF ASIR of NPC in females, MEBC milk excluding butter using International Farm Comparison Network report 2004, MWF whole milk collected from Food Balance Sheets, CHF cheese collected from Food Balance Sheets, BGF butter \& ghee collected from Food Balance Sheets, CRF fresh cream collected from Food Balance Sheets 


\section{Appendix 5}

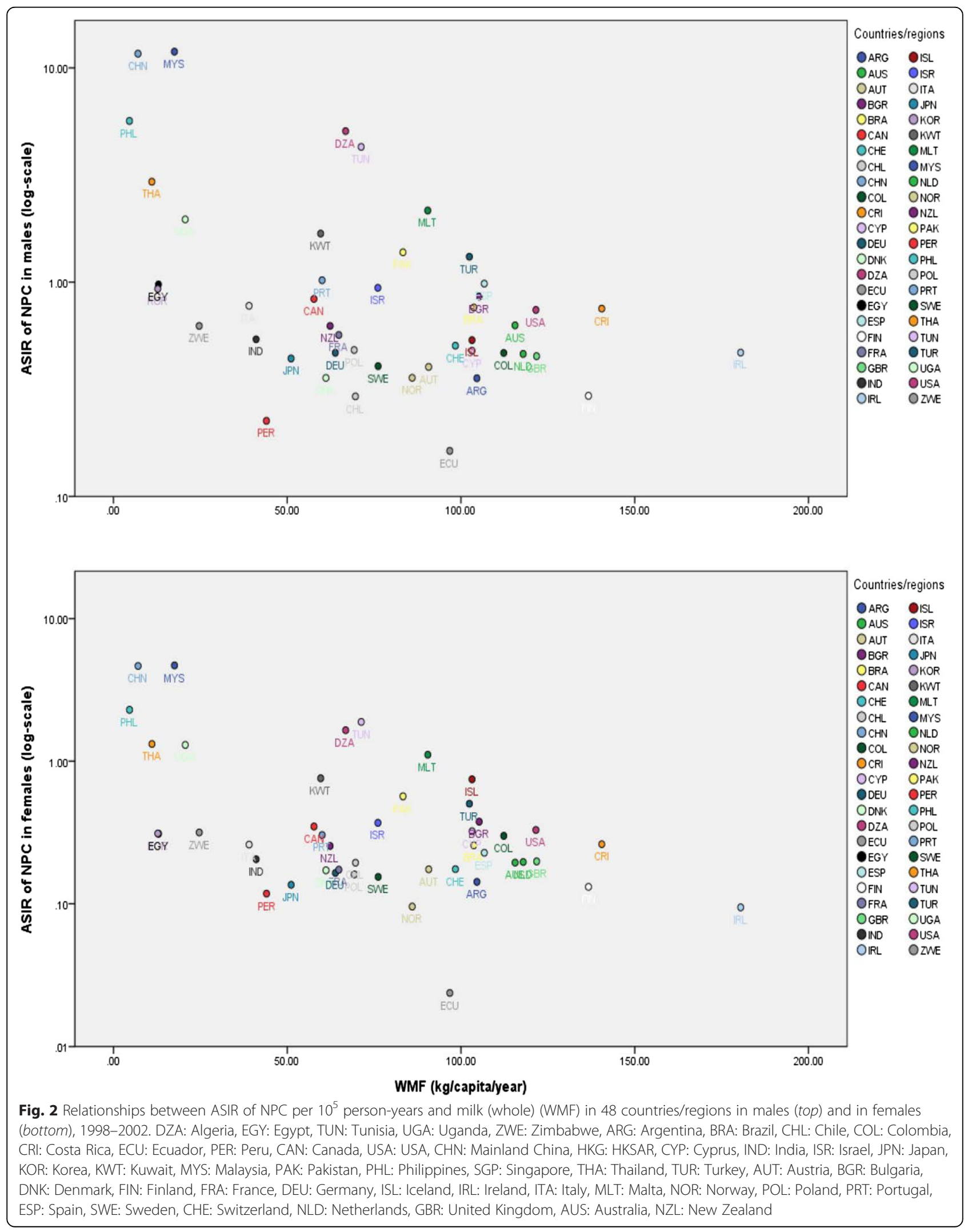




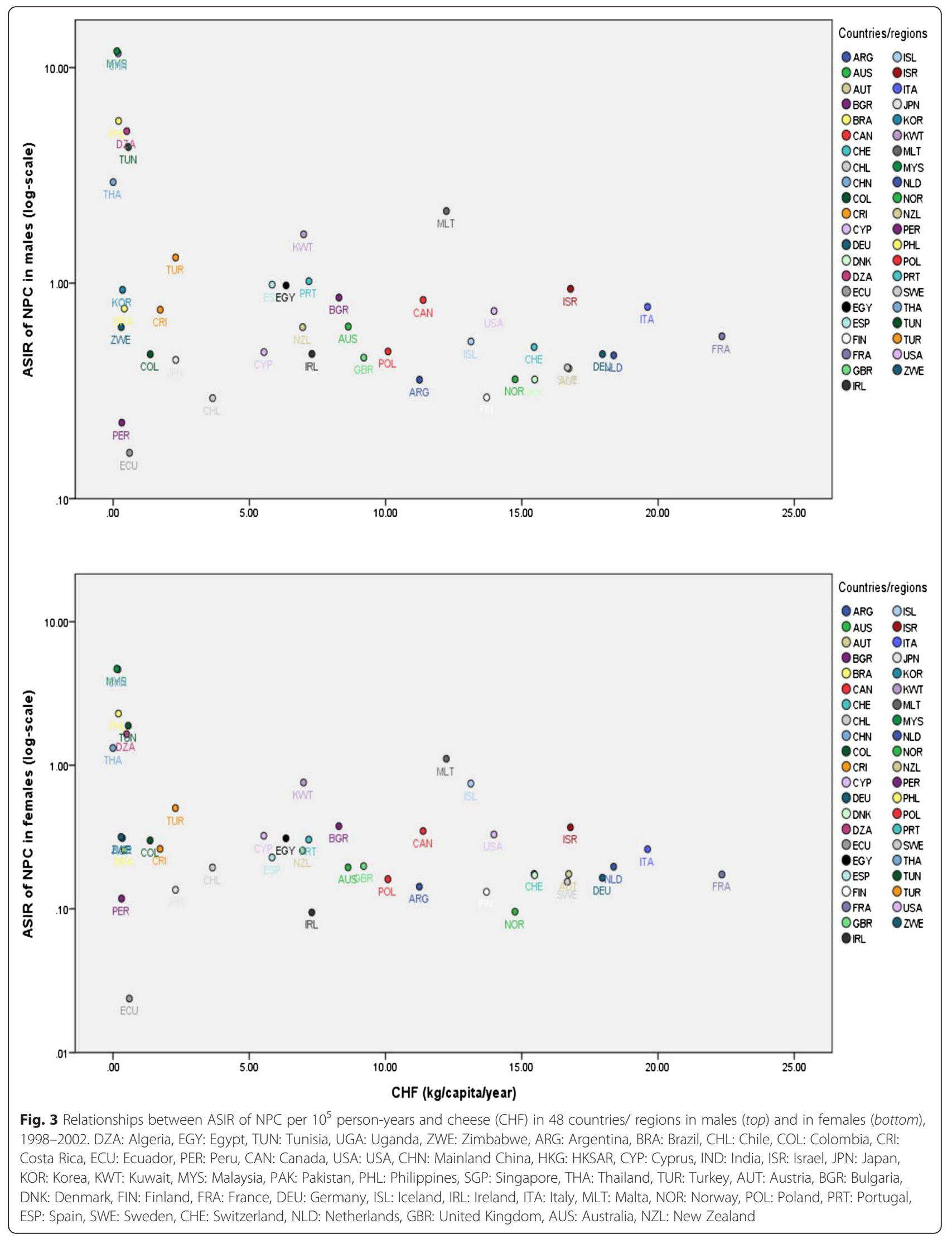




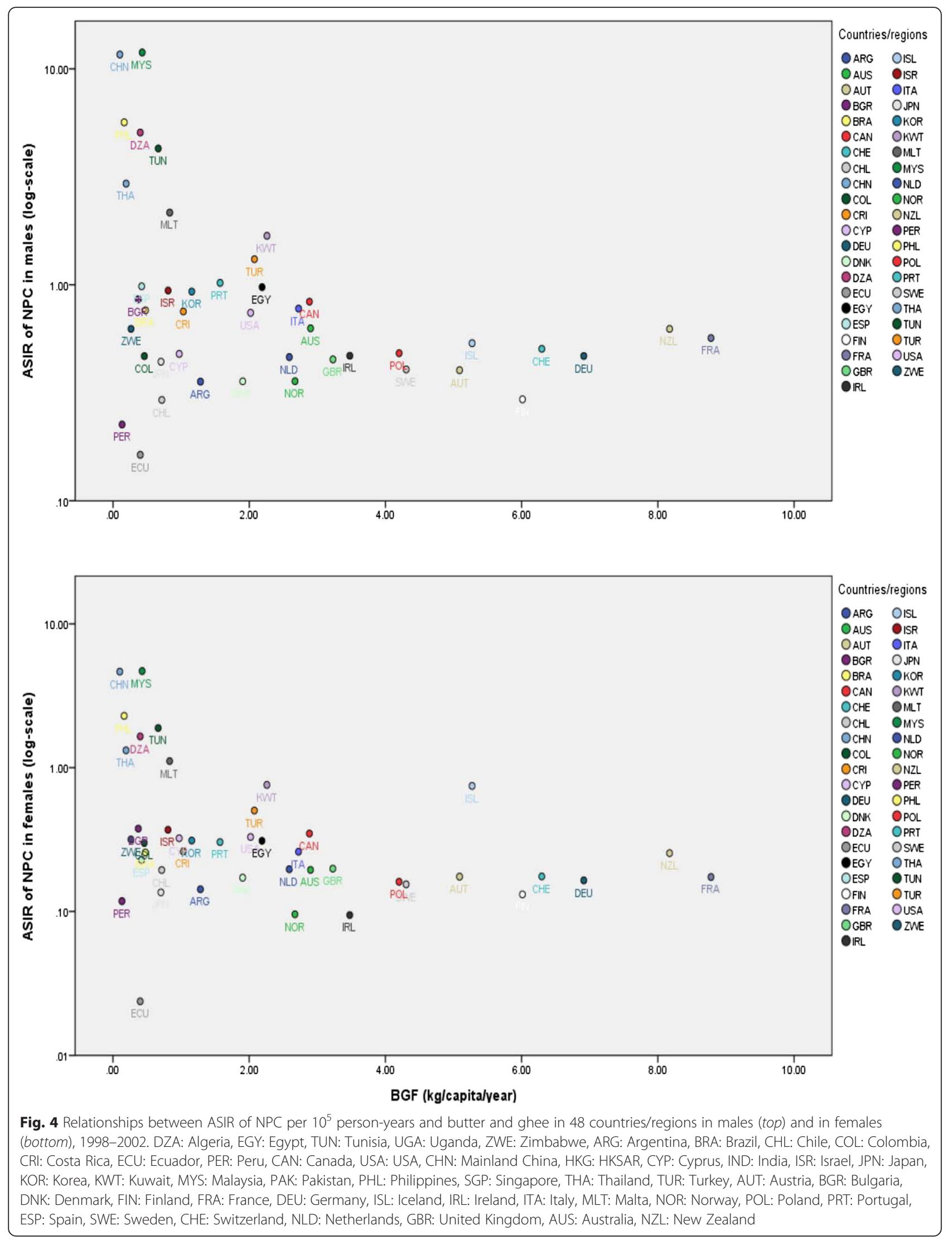




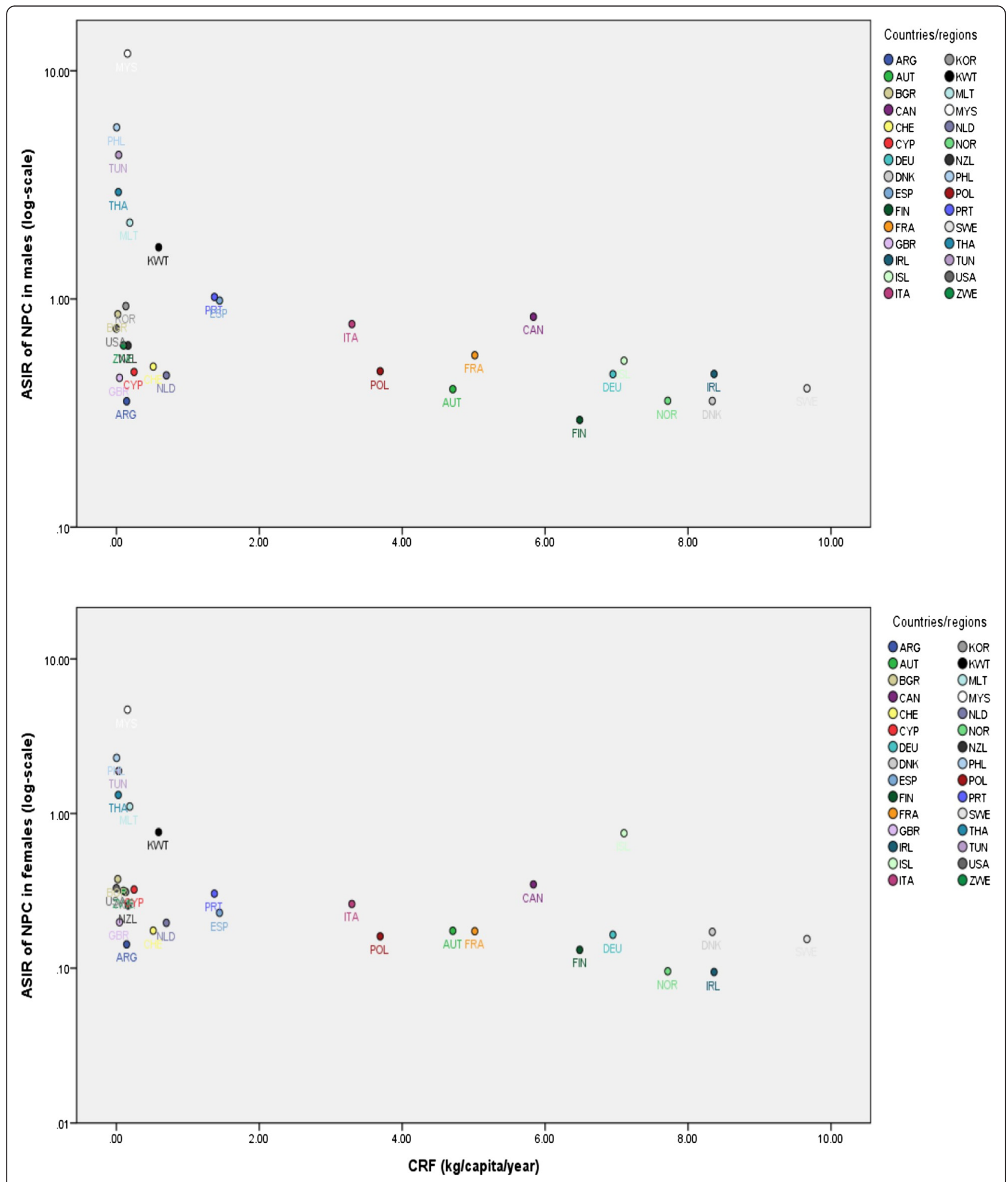

Fig. 5 Relationships between ASIR of NPC per $10^{5}$ person-years and cream (CRF) in 48 countries/regions in males (top) and in females (bottom), 1998-2002. DZA: Algeria, EGY: Egypt, TUN: Tunisia, UGA: Uganda, ZWE: Zimbabwe, ARG: Argentina, BRA: Brazil, CHL: Chile, COL: Colombia, CRI: Costa Rica, ECU: Ecuador, PER: Peru, CAN: Canada, USA: USA, CHN: Mainland China, HKG: HKSAR, CYP: Cyprus, IND: India, ISR: Israel, JPN: Japan, KOR: Korea, KWT: Kuwait, MYS: Malaysia, PAK: Pakistan, PHL: Philippines, SGP: Singapore, THA: Thailand, TUR: Turkey, AUT: Austria, BGR: Bulgaria, DNK: Denmark, FIN: Finland, FRA: France, DEU: Germany, ISL: Iceland, IRL: Ireland, ITA: Italy, MLT: Malta, NOR: Norway, POL: Poland, PRT: Portugal, ESP: Spain, SWE: Sweden, CHE: Switzerland, NLD: Netherlands, GBR: United Kingdom, AUS: Australia, NZL: New Zealand 


\section{Appendix 6}

Table 8 Baseline characteristics of ASIR of NPC, HDI and milk \& dairy products consumption per capita in 48 countries/regions, 1998-2002

\begin{tabular}{|c|c|c|c|c|}
\hline Variable & Mean & SD & Variance & $N$ \\
\hline ASIR in males (per $10^{5}$ ) & 2.06 & 3.64 & 13.27 & 48 \\
\hline ASIR in females (per $10^{5}$ ) & 0.82 & 1.38 & 1.90 & 48 \\
\hline Human Development index (HDI) & 0.83 & 0.12 & 0.02 & 48 \\
\hline Milk excluding butter (MEBC) (kg/capita/year) & 222.48 & 157.98 & 24957.57 & 48 \\
\hline Milk, whole (MWF) (kg/capita/year) & 74.82 & 40.03 & 1602.63 & 46 \\
\hline Cheese (CHF) (kg/capita/year) & 8.49 & 7.21 & 51.86 & 43 \\
\hline Butter \& Ghee (BGF) (kg/capita/year) & 2.29 & 2.17 & 4.72 & 45 \\
\hline Fresh Cream (CRF) (kg/capita/year) & 2.85 & 3.35 & 11.21 & 30 \\
\hline
\end{tabular}

ASIR Age-standardized incidence rate 


\section{Abbreviations}

as $\beta$ : adjusted standardized regression coefficients; auß: adjusted unstandardized regression coefficients; ASIR: age-standardized incidence rates; BGF: butter \& ghee; CRF: fresh cream; CHF: cheese; FAO: Food and Agriculture Organization of the United Nations; HDI: Human Development Index; ICD-10: The International Classification of Diseases $10^{\text {th }}$ Revision; GDP: Gross Domestic Product; HKSAR: Hong Kong Special Administrative Region; MEBC: milk excluding butter; MWF: milk, whole; NPC: nasopharyngeal carcinoma; $\rho$ : Spearman rank correlation coefficients; s $\beta$ : standardized regression coefficients

\section{Competing interests}

The authors have no conflict of interests.

\section{Authors' contributions}

ZMM participated in data collection, conducted data analysis, and drafted the manuscript. CML participated in data collection, and helped to draft the manuscript and revised it critically for important intellectual content. JX, KPC and CMW contributed to the analysis and interpretation of the data, performed the statistical analysis, and revised the manuscript critically for important intellectual content. MLL helped to draft the manuscript and revised it critically for important intellectual content. THL conceived of the study, participated in its design and coordination, and helped to draft the manuscript and revised it critically for important intellectual content. All authors read and approved the final manuscript.

\section{Acknowledgements}

This study supported by Hong Kong RGC Area of Excellence Scheme (Gran Number AoE/M-06/08), and by World Cancer Research Fund UK (WCRF UK) and Wereld Kanker Onderzoek Fonds (WCRF NL), as part of the WCRF International grant programme (grant 2011/460).

\section{Author details}

${ }^{1}$ School of Public Health, Li Ka Shing Faculty of Medicine, The University of Hong Kong, 5/F, William MW Mong Block, 21 Sassoon Road, Hong Kong

S.A.R., China. ${ }^{2}$ Department of Clinical Oncology and Center for Cancer Research, The University of Hong Kong, Hong Kong S.A.R., China. ${ }^{3}$ Center for Nasopharyngeal Carcinoma Research (CNPCR), Research Grants Council Area of Excellence Scheme, The University of Hong Kong, Hong Kong S.A.R., China.

Received: 26 October 2015 Accepted: 15 December 2015

Published online: 21 December 2015

\section{References}

1. Feng BJ. Descriptive, Environmental and Genetic Epidemiology of Nasopharyngeal Carcinoma. In: Busson P, editor. Nasopharyngeal Carcinoma: Keys for Translational Medicine and Biology. New York: Springer; 2013. p. 23

2. Hong Kong Cancer Registry, Hospital Authority. Nasopharyngeal Cancer in 2012. http://www3.ha.org.hk/cancereg/npc_2012.pdf.

3. Silva IS. Cancer Epidemiology: Principles and Methods. International Agency for Research on Cancer. Lyon: World Health Organization; 1999.

4. Lee AW, Ng W, Chan Y, Sze H, Chan C, Lam T. The battle against nasopharyngeal cancer. Radiother Oncol. 2012;104(3):272-8.

5. Jeannel D, Bouvier G, Hubert A. Nasopharyngeal carcinoma: an epidemiological approach to carcinogenesis. Cancer Surv. 1999;33:125-55.

6. Athyros VG, Tziomalos K, Katsiki N, Gossios TD, Giouleme O, Anagnostis P, et al. The impact of smoking on cardiovascular outcomes and comorbidities in statin-treated patients with coronary artery disease: a post hoc analysis of the GREACE study. Curr Vasc Pharmacol. 2013;11(5):779-84

7. Lau HY, Leung CM, Chan YH, Lee AWM, Kwong DLW, Lung ML, et al. Secular trends of salted fish consumption and nasopharyngeal carcinoma: a multi-jurisdiction ecological study in 8 regions from 3 continents. BMC Cancer. 2013;13(1):298

8. World Cancer Research Fund / American Institute for Cancer Research Food, Nutrition, Physical Activity, and the Prevention of Cancer: a Global Perspective. Washington DC: AICR; 2007.

9. Davoodi H, Esmaeili S, Mortazavian A. Effects of Milk and Milk Products Consumption on Cancer: A Review. Compr Rev Food Sci Food Saf. 2013;12(3):249-64
10. Ganmaa D, Li XM, Wang J, Qin LQ, Wang PY, Sato A. Incidence and mortality of testicular and prostatic cancers in relation to world dietary practices. Int J Cancer. 2002;98(2):262-7.

11. Aune D, Rosenblatt DAN, Chan DS, Vieira AR, Vieira R, Greenwood DC, et al. Dairy products, calcium, and prostate cancer risk: a systematic review and meta-analysis of cohort studies. Am J Clin Nutr. 2015;87-117.

12. Ahmad OB, Boschi-Pinto C, Lopez AD, Murray CJ, Lozano R, Inoue M. Age standardization of rates: a new WHO standard. Geneva: World Health Organization; 2001.

13. United Nations, Department of Economic and Social Affairs, Population Division (2013). World Population Prospects: The 2012 Revision. http://esa. un.org/wpp/unpp/panel_population.html. Accessed 17 March 2014.

14. Nicholls J, Niedobitek G. Histopathological Diagnosis of Nasopharyngeal Carcinoma: Looking beyond the Blue Book. In: Busson P, editor. Nasopharyngeal Carcinoma. New York: Springer; 2013. p. 10-22.

15. Ferlay J, Soerjomataram I, Ervik M, Dikshit R, Eser S, Mathers C, et al. GLOBOCAN 2012 v1.0, Cancer Incidence and Mortality Worldwide: IARC CancerBase No. 11 [Internet]. Lyon, France: International Agency for Research on Cancer; 2013. Available from: http://globocan.iarc.fr. Accessed 17 March 2014.

16. Lin JH, Jiang CQ, Ho SY, Zhang WS, Mai ZM, Xu L, et al. Smoking and nasopharyngeal carcinoma mortality: a cohort study of 101,823 adults in Guangzhou, China. BMC Cancer. 2015;15(1):906.

\section{Submit your next manuscript to BioMed Central and we will help you at every step:}

- We accept pre-submission inquiries

- Our selector tool helps you to find the most relevant journal

- We provide round the clock customer support

- Convenient online submission

- Thorough peer review

- Inclusion in PubMed and all major indexing services

- Maximum visibility for your research

Submit your manuscript at www.biomedcentral.com/submit 